\title{
Transnasal endoscopic surgery of sphenoid meningocele associated with pituitary adenoma. A case report
}

\author{
Vlastimil Novaka, Lumir Hrabalek, Jiri Hoza ${ }^{\mathrm{b}}$, Lucie Tuckova ${ }^{\mathrm{c}}$, Daniel Pohlodek $^{\mathrm{a}}$
}

\begin{abstract}
Background. Transsphenoid meningoencephalocele is a congenital anomaly formed by herniation of an ependyma delimited sac through a bony defect into the sphenoid sinus. The sac contains cerebrospinal fluid and neurovascular structures. The prevalence of transsphenoid meningoencephalocele in the adult population is rare. It usually manifests as nasal liquorrhoea.

Methods and Results. This case report presents an adult male who underwent surgery due to suspected pituitary macroadenoma. The surgery was performed endoscopically via the transnasal approach with a surprising finding of true transsphenoid meningoencephalocele. Ectopic solid tissue was found in the sphenoid sinus in which pituitary adenoma was histologically confirmed.

Conclusion. This paper presents a previously unpublished combination of true transsphenoid meningoencephalocele and pituitary adenoma in an adult individual.
\end{abstract}

Key words: transsphenoid meningoencephalocele, pituitary adenoma, nasal liquorrhoea, endoscopic transnasal approach

Received: May 12, 2021; Revised: July 21, 2021; Accepted: August 11, 2021; Available online: August 24, 2021

https://doi.org/10.5507/bp.2021.052

(c) 2022 The Authors; https://creativecommons.org/licenses/by/4.0/

${ }^{a}$ Department of Neurosurgery, University Hospital Olomouc and Faculty of Medicine and Dentistry, Palacky University Olomouc, Czech Republic

${ }^{b}$ Department of Otorhinolaryngology and Head and Neck Surgery, University Hospital Olomouc and Faculty of Medicine and Dentistry, Palacky University Olomouc, Czech Republic

Institute of Clinical and Molecular Pathology, University Hospital Olomouc and Faculty of Medicine and Dentistry, Palacky University Olomouc, Czech Republic

Corresponding author: Vlastimil Novak, e-mail:nvlastimil@seznam.cz

\section{INTRODUCTION}

Transsphenoid type of meningoencephalocele is a congenital anomaly formed by herniation of ependyma delimited sac through a bony defect into the sphenoid sinus. The sac contains cerebrospinal fluid and neurovascular structures, such as the third cerebral ventricle, hypothalamic-pituitary structures, anterior cerebral artery or optic nerve structures ${ }^{1-3}$. It is usually manifested by nasal liquorrhoea or recurrent meningitides, visual disturbances, especially defects of the visual field, endocrine dysfunction and cleft-type defects.

The incidence of transsphenoid meningoencephalocele in the adult population is rare. Only 17 cases have been published according to the available literature ${ }^{1,4-6}$. Combined pituitary adenoma and transsphenoid meningoencephalocele has not been published until now.

\section{METHODS AND RESULTS}

A 71-year-old patient, male, presented with a three-year history of vertigo. Magnetic resonance imaging (MRI) of the brain (Fig. 1) showed intrasellar and intrasphenoid expansion, which corresponded to the suspicion of macroadenoma of the pituitary gland. Supplemented com- puted tomography (CT) of the cranial base demonstrated a bone defect at the level of the sphenoid rostrum, the anterior wall of the sphenoid sinus and the base of the Sella turcica (Fig. 2). The patient underwent an endocrinology examination, demonstrating low levels of free thyroxine (fT4) and high levels of thyroid stimulating hormone (TSH), indicating peripheral hypothyroidism. Full substitution therapy with levothyroxine was newly initiated. Endocrinology examination further revealed mild deficiency of the insulin-like growth factor (IGF-1), slightly higher prolactinaemia, which could indicate compression syndrome in the pituitary stalk area. Gonadotropin levels and corticoid secretion corresponded to the patient's age. Peripheral vision examination did not demonstrate significant visual field impairment. The patient had a history of a cleft palate surgery in childhood.

The patient was indicated to transnasal endoscopic surgery and extirpation of the pituitary adenoma. The surgery was performed in collaboration with a neurosurgeon and an ENT specialist. A nasoseptal vascularized mucosal flap was created at the beginning of the surgery. The approach continued with resection of the dorsal part of the septum in an extent of the vomer. No sphenoid rostrum and no base of the sella turcica were found. The anterior wall of the sphenoid sinus was formed only by the bone-less mucosa. The sphenoid sinus was filled with 
a thin, pulsating membrane similar to the arachnoid. After incision in an extent of $5 \mathrm{~mm}$ (Fig. 3), clear fluid corresponding to cerebrospinal fluid was flowing out. Optic nerve structure was visible through this small defect. There was no solid part of the tumour in the sinus and the sella turcica. Only on the left on the anterior wall of the arachnoid, i.e. in the sphenoid sinus (ectopic localization), there was a bulky, solid tissue with an appearance corresponding to pituitary adenoma. This tissue was submitted for a histological examination. The cerebrospinal fluid leaking defect was reconstructed with the sandwich technique using muscle and fascia lata from the thigh and tissue fibrin glue. Finally, the nasoseptal flap was fixed and nasal tamponade was placed in the nasopharynx.

The patient was monitored at the intensive care unit after the intervention and lumbar drainage was inserted there to prevent nasal liquorrhoea. The patient had transient postsurgical polyuria requiring desmopressin therapy. Nasal tamponade was extracted the second postoperative day. Epistaxis occurred five days after surgery due to haemocoagulopathy, which improved after the treatment. There were no signs of liquorrhoea. The patient was discharged on the 12 th postsurgical day and referred to the endocrinologist. Postsurgical laboratory results confirmed growth hormone deficiency. However, they newly demonstrated pathologically low levels of cortisol secretion based on the 24-hour profile; secretion of gonadotropins FSH and LH virtually disappeared. On the other hand, decompression in the hypothalamic-pituitary region helped normalise the prolactin levels. Histological examination demonstrated, surprisingly in this situation, a pituitary adenoma tissue (GFAP-, S 100+) without proliferative activity (Ki67, p53) (Fig. 4). Follow-up brain MRI at an interval of one month demonstrated significant reduction in the size of the original expansion (Fig. 5). The patient currently shows no neurological symptomatology, he periodically examined at endocrinology department,

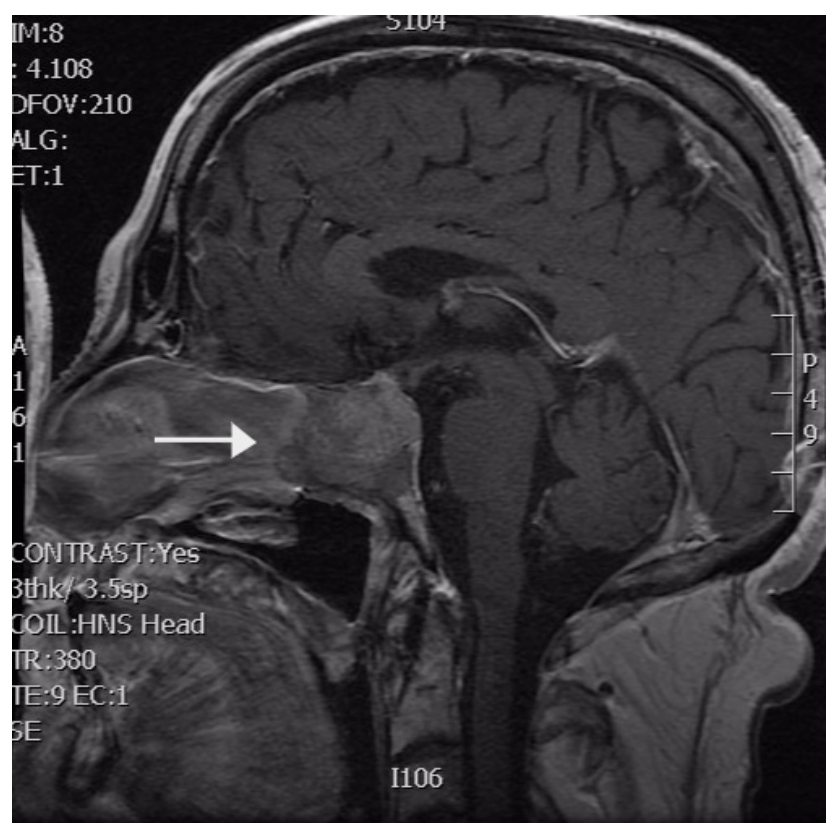

Fig. 1. Contrast-enhanced brain MRI, T1-weighted sagittal scans. Intrasellar and intrasphenoid tumour, indicated by an arrow.

on full substitution therapy of thyroid and glucocorticoid hormones.

\section{DISCUSSION}

In 1972, Suwanwela developed a meningocele classification and divided it into frontal, occipital, parietal, and basal $^{7}$. Basal meningocele occurs in one of 35,000 births and is further divided into transethmoidal, sphenoethmoid, sphenoorbital and transsphenoid ${ }^{7-8}$. The transsphenoid type makes up only $5 \%$ of all basal forms and
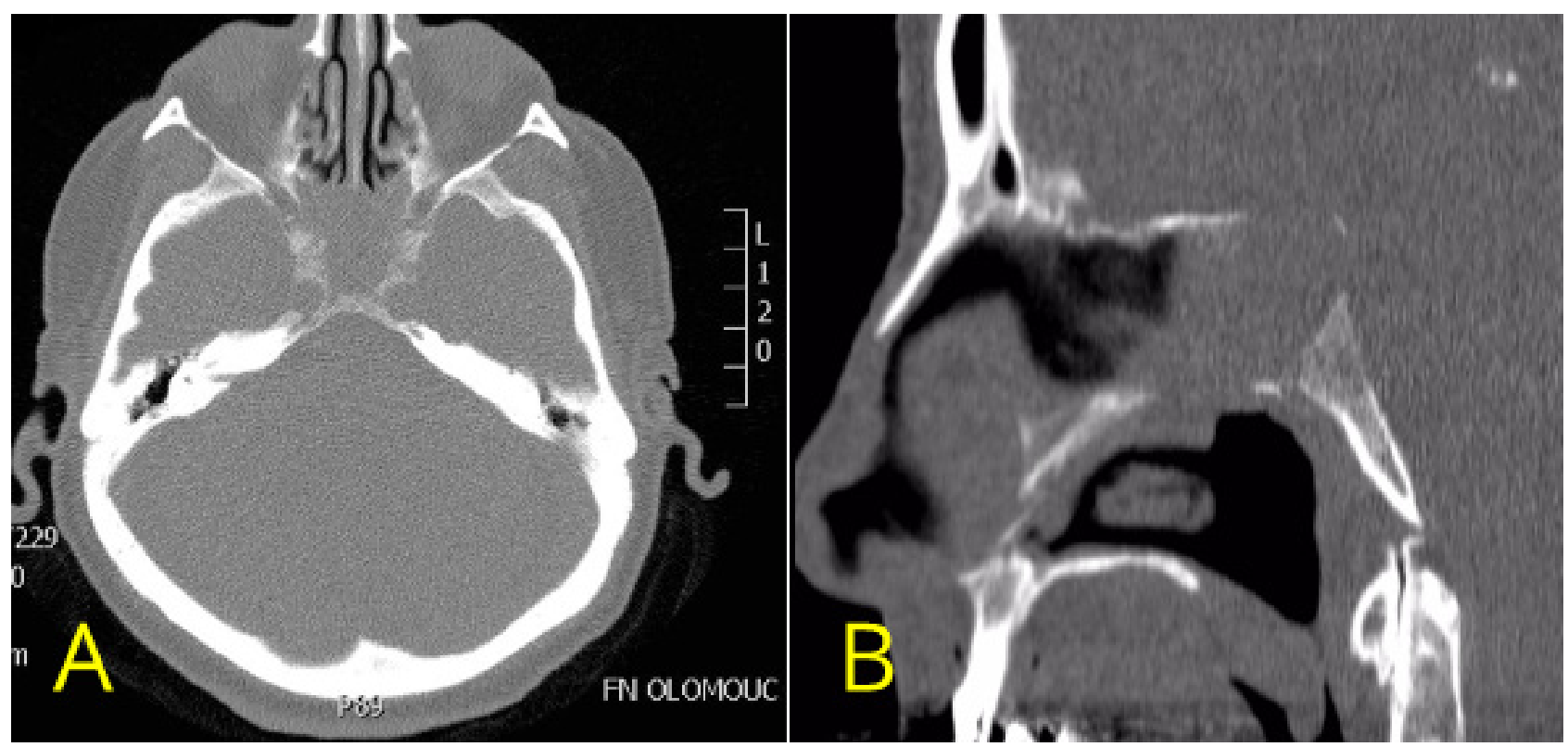

Fig. 2. Brain CT, A - axial scans, B - sagittal scans. Showing the missing vomer, the anterior wall of the sphenoid cavity and the base of the Sella turcica. 


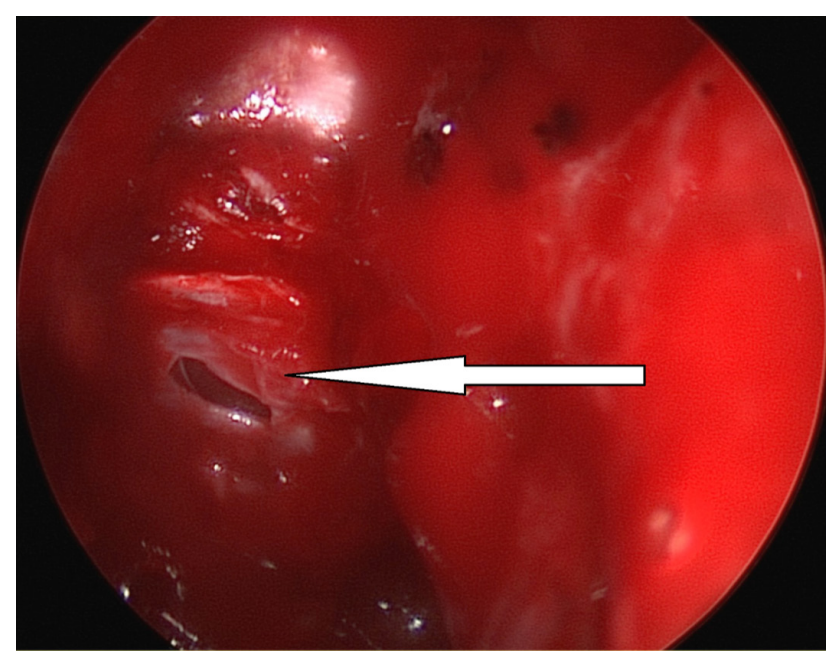

Fig. 3. Image from the endoscope (Storz, Germany, $30^{\circ}$ optics) Visible meningocele defect after incision, indicated by an arrow.
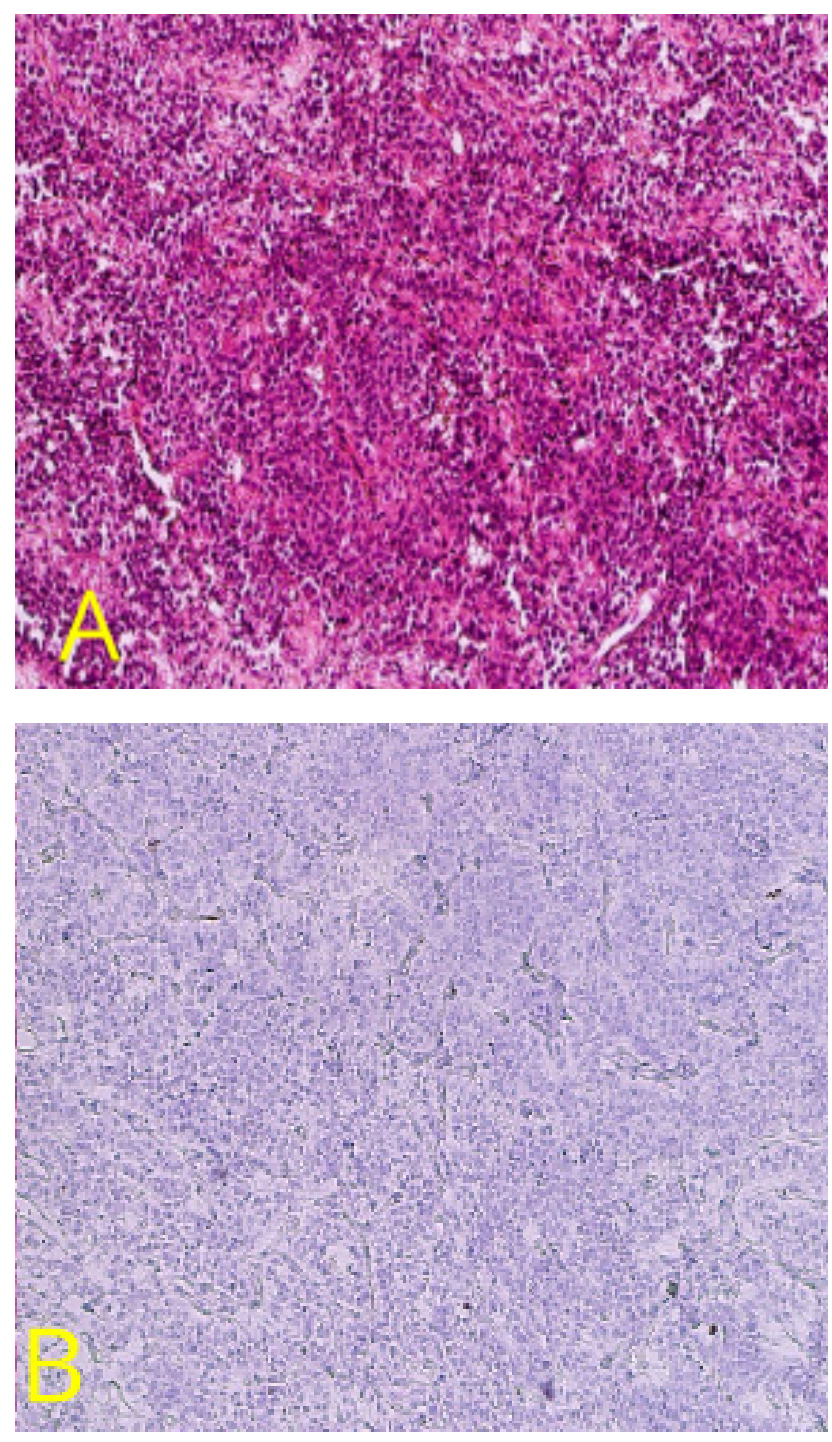

Fig. 4. A - histological examination (hematoxylin-eosin staining, 40x magnification), demonstrating the pituitary adenoma tissue. B - immunohistochemistry examination without signs of increased Ki67 proliferation.

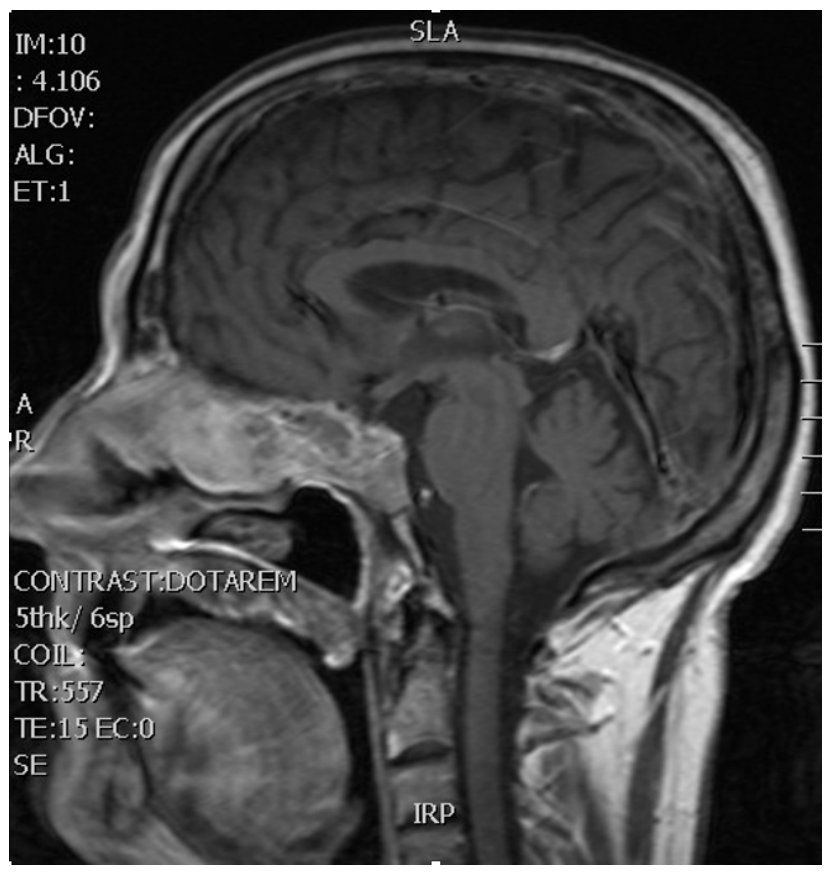

Fig. 5. Postoperative MR with contrast agent, T1 weighted image. Withouth any sign of meningocoele, wound is closed using muscle, adipose tissue, fascia lata, nasoseptal flap and tissue adhesive.

occurs with an incidence of $1 / 700,000$ newborns ${ }^{9}$. Abiko further divides transsphenoid meningoencephalocele into intrasphenoid and true transsphenoid. Intrasphenoid meningoencephalocele stays confined to the sphenoid sinus and does not bulge into the nasopharynx. True transsphenoid meningoencephalocele passes through the ceiling of the sphenoid sinus and bulges into the nasal cavity and nasopharynx ${ }^{4}$. Meningocele may also develop based on a defect in the Sternberg's canal. It is a parasellar bone defect caused by persistence of the lateral craniopharyngeal canal (Sternberg's canal) (ref. ${ }^{6}$ ). In this case we presented true transsphenoid meningoencephalocele.

To date, there have been no reports of a combined sphenoid meningocele with pituitary adenoma. In the case we presented there was an ectopically located adenoma tissue to the left on the anterior wall of the arachnoid. Only Liang published a similar finding of ectopically located adenoma invading the clivus and sphenoid sinus in a combination with empty sella syndrome ${ }^{10}$.

Particularly pseudomeningocele with accumulation of cerebrospinal fluid under the mucosa, without arachnoid lining, should be considered as in addition to pituitary adenoma in differential diagnosis. CT imaging may not reveal a defect in the cranial base and may mimic mucocele or nasal polyp during an endoscopic examination of the nasal cavity ${ }^{11}$. Furthermore, empty sella with arachnoidocele, Rathke's cyst or arachnoid cyst of the sella turcica must be considered. This may manifest clinically as dysfunctional pituitary adenoma visible on a MRI examination as cystic intrasellar expansion containing isointensive or hyperintensive fluid in T1-weighted sequences ${ }^{12}$. 
Sphenoid meningocele surgeries are rarely reported; they had been performed transcranially in the previous years, but the transsphenoid approach has been preferred recently. Surgeries via the transcranial approach are associated with significantly higher morbidity and mortality. Endonasal approach has become a standard tool for management of nasal liquorrhoea based on the Hirsch's report ${ }^{13}$. Microscopic imaging offers a limited visual field and the lateral walls of the sphenoid cavity are not always sufficiently visible. Endoscopic approaches have gained in popularity in recent years, offering the surgeon a possibility "to look around the corner" and leading to lower mortality rate ${ }^{14}$. Muscatello evaluated in his paper the success rate of nasal liquorrhoea management in eight patients. Endonasal endoscopic approach was used in all cases and the cranial base reconstruction was performed using the sandwich method with a collagen matrix, mucoperichondrial flap (nasal septum) and tissue glue. Reliability of the reconstruction was subsequently verified during the surgery by fluorescein administration. Nasal liquorrhoea was successfully stopped in 7 patients. One patient required the second surgery, after which nasal liquorrhoea did not occur any more ${ }^{15}$.

Propagation of the pituitary adenoma masses through a defect of the sella turcica base into the sphenoid cavity is a relatively common finding. As this case report shows, sphenoid meningocele or other pathologies are rather rare. We must be prepared for unusual findings and be able to treat them correctly. Management of sphenoid meningocele is based on perfect cranial base reconstruction to prevent nasal liquorrhoea. In our case, we performed the plastic surgery of a liquorrhoea defect with the sandwich technique using muscle and fascia lata. Creation of the first layer in the base of the sella turcica and a watertight barrier appear to be essential. This is followed by insertion of the second layer into the sphenoid cavity. Finally, the reconstruction is completed using the nasoseptal flap. We apply tissue glue (Tissee ${ }^{\circledR}$ ) between the individual layers of plasty.

\section{CONCLUSION}

True transsphenoid meningocele is a rare congenital malformation which may be manifested by spontaneous liquorrhoea in adulthood. There have been no reports of combined pathology with ectopic pituitary adenoma until now. Despite this finding being rare, it should be kept in mind to ensure the optimal treatment strategy.
Management of transsphenoid meningocele is based on a perfect reconstruction of the cranial base to prevent nasal liquorrhoea and progress of infectious complications.

Acknowledgement: Supported by Ministry of Health, Czech Republic - conceptual development of research organization (FNO1, 0098892).

Author contributions: VN: data collection, literature search, manuscript elaboration and final approval; LH: critical reading, final approval; JH: data collection, critical reading; LT: data collection; DP: literature search, English correction.

Conflict of interest statement: None declared.

\section{REFERENCES}

1. Jabre A, Tabaddor R, Samaraweera R. Transsphenoidal meningoencephalocele in adults. Surg Neurol 2000;54:183-7.

2. Smith DE, Murphy MJ, Hitchon PW, Babin RW, Abu-Yousef MM. Transsphenoidal encephaloceles. Surg Neurol 1983;20:471-80.

3. Yokota A, Matskado Y, Fuwa I, Moroki K, Nagahiro S. Anterior basal encephalocele of the neonatal and infantce period. Neurosurgery 1986;19:468-78.

4. Abiko S, Aoki H, Fudaba H. Intrasphenoidal encephalocele: report of a case. Neurosurgery 1988;22:933-6.

5. Blaivie C, Lequeux T, Kampouridis S, Louryan S, Saussez S. Congenital transsphenoidal meningocele: case report and review of the literature. Am J Otolaryngol 2006;27:422-4.

6. Schick B, Bros D, Prescher A. Sternberg's canal-cause of congenital sphenoidal meningocele. Eur Arch Otorhinolaryngol 2000;257(8):430-2.

7. Suwanwela C, Suwanwela N. A morphological classification of sincipital encephalomeningoceles. J Neurosurg 1972;36:201-11.

8. Matson DD. Neurosurgery of infancy and childhood, 2nd Ed. Springfield, IL: Charles C Thomas, 1969.

9. French BN. Midline fusion defects and defects of formation. In: Youmans JR, editors. Neurosugical Summery. Vol 3. Philadelphia: Saunders; 1982.p.1236-1380.

10. Liang J, Libien J, Kunam V, Shao C, Rao C. Ectopic pituitary adenoma associated with an empty sella presenting with hearing loss: case report with literature review. Clin Neuropathol 2014;33:197-202.

11. Vaezi A, Snyderman CH, Saleh HA, Carrau RL, Zanation A, Gardner P. Pseudomeningoceles of the sphenoid sinus masquerading as sinus pathology. Laryngoscope 2011;12:2507-13.

12. Dubuisson AS, Stevenaert A, Martin DH, Flandroy PP. Intrasellar arachnoid cysts. Neurosurgery 2007;61:505-13.

13. Hirsch $O$. Successful closure of cerebrospinal fluid rhinorrhea by endonasal surgery. Arch Otolaryngol 1952;56:1-13.

14. Aydin S, Cavallo LM, Messina A, Fabbro MD, Cappabianca P, Barlas $\mathrm{O}$, Divitis ED. The endoscopic endonasal trasnsphenoidal approach to the sellar and suprasellar area. Anatomic study. J Neruosrugery Sci 2007;51:129-38.

15. Muscatello L, Lenzi R, Dallan I, Seccia V, Marchetti M, SellariFranceschini S. Endoscopic transnasal management of cerebrospinal fluid leaks of the sphenoid sinus. J Craniomaxillofac Surg 2010;38:396-402. 